\title{
A Simple Model of the Effect of the Kerguelen Plateau on the Strength of the Antarctic Circumpolar Current.
}

\author{
David J. Webb
}

Institute of Oceanographic Sciences Deacon Laboratory, Wormley, Godalming, Surrey GU8 5UB, U.K.

\begin{abstract}
.
The strong westerly winds of the Southern Ocean drive a northwards Ekman transport which increases in magnitude from $9 \mathrm{~Sv}$, at the southern latitudes of Drake passage, to a maximum of $37 \mathrm{~Sv}$ at $45^{\circ} \mathrm{S}$. The return flow can occur as a western boundary current along the coasts of South America and the Antarctic Peninsula but at depths above 3000m such a boundary current cannot cross Drake Passage and so another mechanism must be involved.

In this paper it is shown that one possible mechanism is for the flow to continue south as a western boundary current attached to the islands and other topographic barriers, which span the latitudes of the passage. A simple model of this process shows that it also generates a strong circumpolar current.

The model is then applied to the Southern Ocean using the Kerguelen Plateau as the second topographic barrier. The Kerguelen Plateau occludes the Drake Passage between 1600m and 3000m - depths which other model studies have shown to include the Ekman return flow. Using Hellerman and Rosenstein estimates of the wind stress, the model predicts an Antarctic Circumpolar Current with a transport of $151 \mathrm{~Sv}$. This is in reasonable agreement with observations and other model studies. The model does less well south of the Kerguelen Plateau, where it predicts a second strong current. In practice such a current is not observed.
\end{abstract}

\section{Introduction}

Munk and Palmn (1951) showed that if the wind stress driving the Circumpolar Current is balanced only by lateral kinematic eddy viscosity, then the transport in the Circumpolar Current is unrealistically large. They showed that if the wind stress is 2 dynes $\mathrm{cm}-2$, then the total transport is of order 1,000 to $50,000 \mathrm{~Sv}$ depending on the assumed width of the channel.

They considered a number of possible processes which could balance the torque due to the wind stress and concluded that the meridional circulation exported absolute angular momentum near the 
surface and imported it at a lower level, where it was transferred to the topography. They actually proposed the Benguela and Peru currents as the agents for exporting the angular momentum, but in practice the surface Ekman transport is sufficient. At $58^{\circ} \mathrm{S}$, an eastwards stress of 2 dynes $\mathrm{cm}-1$ (the Munk and Palmn value) corresponds to a total Ekman transport to the north of $35.7 \mathrm{~Sv}$. For the return flow Munk and Palmn proposed a southward drift of water at depths between 1000 and $4000 \mathrm{~m}$. They suggested that as it moved south it would be accelerated towards the east by the Coriolis force (conserving angular momentum around the Earth's axis) and this would be retarded by pressure forces acting against the submarine ridges balancing the stress exerted by the wind on the water's surface.

Johnson and Bryden (1989) recently objected to this proposal on the basis that it required an input of buoyancy to convert deep water to lighter surface water, whereas conventional air-sea-ice exchange considerations argued for a large buoyancy loss over the Southern Ocean. Instead they proposed that the wind stress is balanced by an eddy form drag. However analysis of data from the FRAM model (Saunders and Thompson, 1992) shows that, in the model at least, the Ekman layer is present and of the expected magnitude. In the region where the model Ekman layer is strongest, between $40^{\circ} \mathrm{S}$ and $60^{\circ} \mathrm{S}$, the average heat flux it requires is $4 \mathrm{Wm}^{-2}$. This is smaller than the errors in the estimates of air-sea heat fluxes. Thus the presence of an Ekman layer in the Southern Ocean cannot be ruled out using the heat flux arguments. If all the Ekman return flow occurs below the sill level in Drake Passage, as could happen in a stratified ocean with a suitable thermohaline circulation, then the north-south flow can occur as a western boundary current. The angular momentum that the water earlier gained from the wind is now lost to the topography via the east-west pressure gradient. In this case no circumpolar current would form.

If part of the return flow occurs above the sill then another mechanism is needed to apply a force to the flow, to change its angular momentum and allow it to continue its journey south. Invoking horizontal or vertical momentum transfers within the ocean produces the same problems as before. However these are not the only mechanisms that need be involved and in this paper a new mechanism is put forward.

It is proposed that the southward return flow occurs in western boundary currents following the flanks of topographic features which span the latitudes of Drake Passage. An example is the Kerguelen Plateau, which has a maximum depth of $1600 \mathrm{~m}$ at the latitudes of Drake Passage and so occludes the channel below this depth. It is shown that such flows are stable and that the southward return flow generates a large eastwards current.

To illustrate the mechanism, we first consider a series of thought experiments involving steady state source and sink flows. Each of the sources and sinks lies near a western boundary and the resulting idealised current field is made up of western boundary currents and zonal jets. Confirmation that the solutions are realistic and stable is obtained by introducing similar source and sink terms into a one layer reduced gravity model. Finally the application of this theory to the Southern Ocean is 
discussed.

\section{Simple Reduced Gravity Model}

Experience with models of simple unstratified ocean basins (Stommel, 1957, 1965; Munk and Carrier, 1950; LeBlond and Mysak, 1978; Gill, 1982) has shown that time independent oceanic flows can often usefully be classed either as western boundary currents, zonal jets or interior (Sverdrup) flows. The effects of time dependence, topography and stratification complicate the picture but the general classification still remains. In this paper we discuss the flow across a simple occluded channel in terms of this simple classification and with the expectation that the real ocean may be different in detail but not in substance.

Consider a layer of fluid at mid-depths within the ocean. Let $u$ and $v$ be the eastward and northward components of velocity, $p$ the pressure, $x$ and $y$ the eastwards and northwards coordinates, $f$ the coriolis parameter which varies with $y$ and $A$ the horizontal viscosity coefficient. If the vertical viscosity term is small enough to be neglected, then the horizontal momentum equations are,

$\rho\left(\frac{\partial u}{\partial t}+\left(u \frac{\partial}{\partial x}+v \frac{\partial}{\partial y}\right) u-f(y) v\right)=-\frac{\partial p}{\partial x}+\frac{\partial}{\partial x}\left(A \frac{\partial u}{\partial x}\right)+\frac{\partial}{\partial y}\left(A \frac{\partial u}{\partial y}\right)$,

$\rho\left(\frac{\partial v}{\partial t}+\left(u \frac{\partial}{\partial x}+v \frac{\partial}{\partial y}\right) v+f(y) u\right)=-\frac{\partial p}{\partial y}+\frac{\partial}{\partial x}\left(A \frac{\partial v}{\partial x}\right)+\frac{\partial}{\partial y}\left(A \frac{\partial v}{\partial y}\right)$.

The boundary condition is that the velocity $(u, v)$ is zero on all boundaries. In the rest of the paper the density $\rho$ is assumed to be constant.

\subsection{Western Boundary Current}

If the ocean has a steady western boundary current running along a straight boundary at $x$ equal to 0 , then within the boundary current, $u$ is zero and $v$ is independent of y. Equations 1 and 2 then become,

$$
\begin{aligned}
-\rho f(y) v & =-\frac{\partial p}{\partial x}, \\
0 & =-\frac{\partial p}{\partial y}+\frac{\partial}{\partial x}\left(A \frac{\partial v}{\partial x}\right) .
\end{aligned}
$$

Normally the shallow water equations are solved by eliminating the pressure term and obtaining an equation for a stream function (e.g. Munk 1950). However for the problems discussed later it is more instructive to work with the pressure field.

Integrating equation 3 away from the boundary at $x$ equal to 0 ,

$\rho f(y) F_{y}(x)=p(x, y)-p(0, y)$,

where $F_{y}(x)$ is the integrated flux per unit depth,

$F_{y}(x)=\int_{0}^{x} v d x^{\prime}$ 
Equation 5 shows that the pressure drop across the current depends only on the total flux and the latitude. In the absence of any other currents, the pressure far off-shore will be constant and independent of $x$ or $y$. Thus from Eqn. 5 the pressure at the boundary is given by,

$p(0, y)=p_{\infty}-\rho f(y) F_{t o t}$,

where $p_{\infty}$ is the off-shore pressure and $F_{t o t}$ is the total transport in the western boundary current. Note that in a stable western boundary current, the pressure drop along the current due to viscous effects (Eqn. 4), must match the change in the pressure difference across the current due to changes in $f$ (Eqn. 7).

\subsection{East-west Jets}

Although there is a considerable literature on western boundary currents, less work appears to have been carried out on zonal jets, except at the equator (Gill, 1975). Consider an east-west jet in which $u$ is large compared with $v, u$ is symmetric about the centre of the jet, $v$ is antisymmetric and terms involving $\partial / \partial x$ are small compared to the those involving $\partial / \partial y$. Neglecting small terms, Eqns. 1 and 2 become,

$$
\begin{array}{r}
-\rho f(y) v=-\frac{\partial p}{\partial x}+\frac{\partial}{\partial y}\left(A \frac{\partial u}{\partial t}\right), \\
\rho f(y) u=-\frac{\partial p}{\partial y} .
\end{array}
$$

Integrating eqn. 8 from $y$ to infinity, and assuming that $f$ is roughly constant in the region of the jet, gives,

$\rho f\left(y_{0}\right) F_{x}(y)=p(x, y)-p^{+}$,

where $y_{0}$ is the $y$ coordinate of the centre of the jet, $p^{+}$is the pressure as $y$ tends to plus infinity and the flux term $F_{x}(y)$ is defined by,

$F_{x}(y)=\int_{0}^{\infty} u d y^{\prime}$

As with a western boundary current, the total pressure drop across the jet is related to the total flux,

$p^{+}-p^{-}=-\rho f(y) F_{x}(0)$.

$F_{x}(0)$ is the total flux and $p^{-}$is the pressure on the boundary.

Consider a layer of fluid with no vertical velocities through its upper or lower surfaces. The flow field within the layer can then be described by a stream function $\psi$, for which

$$
\begin{aligned}
& H u=-\frac{\partial \psi}{\partial y} \\
& H v=\frac{\partial \psi}{\partial x} .
\end{aligned}
$$


$H$ the layer thickness is assumed to be approximately constant. Substituting for $u$ and $v$ in eqns. 8 and 9 , assuming $A$ is constant and taking the curl of the two equations gives,

$-\rho \beta \frac{\partial \psi}{\partial x}=-A \frac{\partial^{4} \psi}{\partial y^{4}}$.

This has the form of a diffusion equation, but one in which the $-x$ coordinate has the role of time and bi-harmonic $\left(A \partial^{4} / \partial y^{4}\right)$ diffusion has replaced the normal harmonic $\left(A \partial^{2} / \partial y^{2}\right)$ diffusion.

As shown in Appendix A, a point source or sink on the eastern boundary results in an east-west jet, which becomes wider towards the west. Within the jet there appears to be a balance between viscosity, which works to spread the jet, and Rossby waves propagating from the eastern boundary, which work to constrain it in a north-south direction. In the next section we approximate this flow by a single narrow jet.

\section{Thought Experiments}

\subsection{Flow in an Enclosed Basin}

Consider first the problem of a rectangular ocean, with a partial barrier extending northwards from the centre of the southern coastline. There is a source of water in the north-west corner of the basin with an equal sink in the corner formed where the eastern side of the barrier meets the southern boundary. The only steady state flow that can result, made up of western boundary currents and an east-west jet, is that shown in figure 1 .

If the flux of water is F, then from Eqn. 12, the pressure difference between regions 1 and 2, is,

$P_{1}-P_{2}=-\rho f\left(y_{1}\right) F$

where $f\left(y_{1}\right)$ is the Coriolis term at the latitude of the jet.

In addition to the pressure drop across the jet, there is also a pressure drop along each of the western boundary currents. This is given by Eqn. 4 .

\subsection{Zonal Channel with Interlacing Barriers}

The solution is the same if the ocean is periodic in the east-west direction so that the apparent western and eastern boundaries are formed by the same north-south barrier. However if part of the barrier is removed, say the section between points $\mathrm{A}$ and $\mathrm{B}$ of figure 1, then the original flow pattern can no longer be a steady state solution. This is because there is now a pressure gradient between the two regions previously separated by the barrier.

A solution for this case can be found by adding a second east-west jet (see figure 2), If the pressures in the two regions 1 and 2 are $P_{1}$ and $P_{2}$ as before and if $F_{1}$ and $F_{2}$ are the fluxes in the two 
east-west jets which are at latitudes $y_{1}$ and $y_{2}$, then,

$P_{1}-P_{2}=-\rho f\left(y_{1}\right) F_{1}$,

$P_{1}-P_{2}=-\rho f\left(y_{2}\right) F_{2}$.

But,

$F_{1}=F_{2}+F$

so,

$F_{1}=\frac{f\left(y_{2}\right)}{f\left(y_{2}\right)-f\left(y_{1}\right)} F$,

$F_{2}=\frac{f\left(y_{1}\right)}{f\left(y_{2}\right)-f\left(y_{1}\right)} F$.

Thus a zonal channel with interlacing boundaries can support a north-south transport through the formation of a zonal current. This is a key result which is developed in the rest of this paper. Equation 18 shows that, except in cases where equatorial regions are involved, the magnitude of the zonal current will be larger than that of the meridional current. It will also generally be largest when the latitudes $y_{1}$ and $y_{2}$ are closest together.

The theory is easily extended to a series of interlacing barriers. The solution for four barriers is,

$F_{2}=\frac{f\left(y_{1}\right)}{f\left(y_{2}\right)-f\left(y_{1}\right)+f\left(y_{4}\right)-f\left(y_{3}\right)} F$,

where $y_{3}$ and $y_{4}$ are the latitudes of the second pair of northern and southern barriers respectively.

The extra interlacing barriers reduce the zonal transport needed to support the north-south flux.

\subsection{An Occluding Island}

Next consider a zonal channel containing a north-south barrier with a single gap, and an island which blocks direct east-west flow at the latitudes of the gap. The source and sink are in the north-west and south-west corners formed where the barrier meets the northern and southern boundaries.

The steady state solution for this case, made up of western boundary currents and east-west jets, is shown in figure 3. If the pressures in regions 1,2 and 3 of figure 3 are $P_{1}, P_{2}$ and $P_{3}$, then the fluxes $F_{1}, F_{2}$, are given by eqns 18 and the fluxes associated with the southern current system are,

$F_{3}=\frac{f\left(y_{4}\right)}{f\left(y_{4}\right)-f\left(y_{3}\right)} F$,
$F_{4}=\frac{f\left(y_{3}\right)}{f\left(y_{4}\right)-f\left(y_{3}\right)} F$.

Thus a north-south current can cross a zonal channel containing an occluding island, but only at the cost of driving two strong zonal currents. 
If two or more islands combine to occlude the channel, then extra zonal currents are generated. The cases involving two islands are shown in figures $4 \mathrm{a}$ and $4 \mathrm{~b}$. In both cases,

$$
\begin{array}{lr}
\left(P_{1}-P_{3}\right)=-\rho f_{1} F_{1}=-\rho f_{2} F_{2}, & F_{1}=F_{2}+F, \\
\left(P_{3}-P_{4}\right)=-\rho f_{a} F_{a}=-\rho f_{b} F_{b}, & F_{a}=F_{b}+F, \\
\left(P_{4}-P_{2}\right)=-\rho f_{3} F_{3}=-\rho f_{4} F_{4}, & F_{3}=F_{4}+F . \\
& \\
F_{2}=\left(f_{1} /\left(f_{2}-f_{1}\right)\right) F, & F_{1}=\left(f_{2} /\left(f_{2}-f_{1}\right)\right) F, \\
F_{b}=\left(f_{a} /\left(f_{b}-f_{a}\right)\right) F, & F_{a}=\left(f_{b} /\left(f_{b}-f_{a}\right)\right) F, \\
F_{4}=\left(f_{3} /\left(f_{4}-f_{3}\right)\right) F, & F_{3}=\left(f_{4} /\left(f_{4}-f_{3}\right)\right) F .
\end{array}
$$

Here and in the rest of the paper $f_{1}$ is used to denote $f\left(y_{1}\right)$ etc. The total zonal flow $F_{\text {tot }}$ is,

Case $4_{a}: \quad F_{t o t}=F_{2}+F_{b}+F_{4}+F$,

Case $4_{b}: \quad F_{\text {tot }}=F_{2}+F_{b}+F_{4}+2 F$.

From these results, it is apparent that a meridional flow is also possible when the channel is occluded by a series of two or more islands (or other topographic feature) and that each additional island in the series introduces an additional strong zonal jet.

\subsection{Secondary Islands}

It is also of interest to know the effects of secondary islands or topographic features which interfere with the flow but otherwise are not required to occlude the channel. These are considered in more detail in Appendix B. It is found that such additional islands either have no effect on the total zonal transport flow or increase it by an amount less that that produced by an additional occluding island (equation 22).

\subsection{An Island Sink}

So far all of the cases considered have placed the sources and sinks at the northern and southern boundaries. In the final case considered, that of figure 5, the sink is placed in the western boundary of one of the islands. As will be discussed later, this may have application when discussing the role of the Scotia Arc, the island arc to the east of Drake passage.

From figure 5,

$P_{2}-P_{3}=-\rho f_{5}, \quad F_{5}=-\rho f_{6} F_{6}, \quad F_{5}+F_{6}=F$.

Thus,

$F_{5}=\frac{f_{6}}{\left(f_{6}-f_{5}\right)} F, \quad F_{6}=-\frac{f_{5}}{\left(f_{6}-f_{5}\right)} F$. 
When compared to the source and sink terms, the flow $F_{5}$ is large and positive, and the flow $F_{6}$ is large and negative. Together they form part of a small recirculating cell. (The connection with a small gyre driven by Ekman suction is fairly obvious). In addition,

$$
\begin{aligned}
F_{1}^{\prime} & =\frac{f_{6}+f_{2}}{f_{2}-f_{1}}\left(-F_{6}\right), \\
& =\frac{f_{6}+f_{2}}{f_{6}-f_{5}} \frac{f_{5}}{f_{2}} F_{1}, \\
F_{2}^{\prime} & =F_{1}^{\prime}-F_{6}, \\
F_{4}^{\prime} & =\frac{f_{6}-f_{3}}{f_{4}-f_{3}}\left(-F_{6}\right), \\
F_{3}^{\prime} & =F_{4}^{\prime}+F_{6} .
\end{aligned}
$$

Note that with this geometry, the two northern currents, $F_{1}^{\prime}$ and $F_{2}^{\prime}$, are large compared to both $F_{6}$ and to their values in the standard occluded channel case (Eqn. 22).

\section{Tests with a Numerical Model}

The solutions discussed in the above thought experiments are consistent with the conservation equations of momentum and mass. However we have not shown that they are stable or that they are solutions likely to arise in practice.

These properties have been checked for the most important case, that of fig 3, using a one-layer reduced gravity numerical model. The model solves the linearised momentum equations and a linearised conservation of volume equation,

$$
\begin{aligned}
\rho\left(\frac{\partial u}{\partial t}-f(y) v\right) & =-g \delta \rho \frac{\partial h}{\partial x}+\frac{\partial}{\partial x}\left(A \frac{\partial u}{\partial x}\right)+\frac{\partial}{\partial y}\left(A \frac{\partial u}{\partial t}\right), \\
\rho\left(\frac{\partial v}{\partial t}+f(y) u\right) & =-g \delta \rho \frac{\partial h}{\partial y}+\frac{\partial}{\partial x}\left(A \frac{\partial v}{\partial x}\right)+\frac{\partial}{\partial y}\left(A \frac{\partial v}{\partial y}\right), \\
\partial h / \partial t+H\left(\frac{\partial u}{\partial x}+\frac{\partial v}{\partial y}\right) & =0
\end{aligned}
$$

where $H$ is the mean layer thickness, $h$ the change in thickness from the mean and $\delta \rho$ the change in density between layers.

The equations are solved using a finite difference approximation to the gradient terms on an Arakawa B-grid (Messinger and Arakawa 1976). The model has a grid size of $20 \mathrm{~km}$, with 202 points in the east-west direction and 126 in the north-south direction. The coriolis term is assumed to be linear in $\mathrm{y}$,

$f(y)=f_{c}+\beta_{c} y$

where $f_{c}$ and $\beta_{c}$ are the values of the coriolis term and its north-south gradient at the central latitude of the model $\left(60^{\circ} \mathrm{S}\right)$. 
The model uses a leapfrog timestepping scheme with a 1800 s timestep. A Euler-backward scheme is used every 36 timesteps to prevent timesplitting. In the model, $H$ equals $1000 \mathrm{~m}, g \delta \rho / \rho$ equals $0.01 \mathrm{~ms}^{-2}$, and $A / \rho$ equals $1000 \mathrm{~m}^{2} \mathrm{~s}^{-1}$.

\subsection{The First Test with the Numerical Model}

A source term of $1 \mathrm{~Sv}\left(1 \mathrm{~Sv}=10^{6} \mathrm{~m}^{3} \mathrm{~s}^{-1}\right)$ was added in the north-west corner of the domain, spread over two grid points next to the northern boundary. Matching sink terms were added in the south-west corner. Starting from rest the model was run until, with the exception of a small residual oscillation, it had reached a steady state.

The resulting height field, related to the pressure by,

$p=g \delta \rho h$,

and the stream function field, found by integrating the eastward velocity field from the northern boundary, are shown in figure 6. Note that the stream function differs by $1 \mathrm{~Sv}$ between the western and eastern boundaries.

The flow calculated by the numerical model is close to that of figure 3 but there are differences associated both with the western boundary current regions and the east-west jets. In the numerical model the western boundary currents are not simple jets but are fairly broad structures with offshore recirculation regions. Munk (1950, eqns 21 and 24) showed that the recirculation regions resulted from the use of the Laplacian horizontal viscosity term.

The east-west currents in the numerical model are also not narrow jets as was assumed above but, as expected from the analysis of Appendix A, they are narrowest at their eastern end and spread out roughly symmetrically north-south towards the west. The axes of the jets are also not aligned exactly with the latitude of the topographic feature controlling them but are offset by about $100 \mathrm{~km}$.

From the figures, this offset appears to be determined by the width of the boundary layer as it forms to go around the topography in the east. The latter should be determined by the width of the Munk boundary layer in the western boundary current. This equals $(A /(\rho \beta))^{1 / 3}$, or $44.4 \mathrm{~km}$.

In addition to these differences, there is a small amount of recirculation, and corresponding small slopes in the height field, in the regions where the earlier thought experiments assumed that the pressure field was constant. As inertial terms are missing from this model, these are probably a further result of the Laplacian viscosity term.

The numerical model transports in the northern and southern jets to the west of the island have been estimated from the stream function to be,

$F_{1}=15.4 \mathrm{~Sv}, \quad F_{4}=15.6 \mathrm{~Sv}$,

with a possible error of approximately $0.5 \mathrm{~Sv}$ due to the slow residual oscillation in the flow field. The latter has a period equal to the transit time of long westward propagating Rossby waves across the model and is a residual of the initial start up process. 
From equations 3.3, the predicted flows in the two jets are,

$$
\begin{aligned}
& F_{1}=\frac{f_{2}}{f_{2}-f_{1}} F, \\
& F_{4}=\frac{f_{3}}{f_{4}-f_{3}} F .
\end{aligned}
$$

If $y_{1}$ and $y_{4}$ are taken to be the latitudes of the northern and southern limits of the island and $y 2$ and $\mathrm{y} 3$ are of the northern and southern limits of the passage then,

$F_{1}=20.8 \mathrm{~Sv}, \quad F_{4}=21.7 \mathrm{~Sv}$.

If instead, y1 and $\mathrm{y} 3$ are moved north by $100 \mathrm{~km}$ and $\mathrm{y} 2$ and $\mathrm{y} 4$ are moved south by the same amount then,

$F_{1}=14.7 \mathrm{~Sv}, \quad F_{4}=15.5 \mathrm{~Sv}$.

These figures are in reasonable agreement with the numerical model results. The results also confirm that the original solution was stable and that it is one likely to arise in practice.

\subsection{The Second Test with the Numerical Model}

So far we have considered the case of a single density layer with localised sources and sinks on the boundary. If the layer is in fact the whole ocean, and is driven by a varying wind field, then instead of the localised sources and sinks there would be a vertical flux into or out of the Ekman layer depending on the curl of the wind stress. In the Southern Ocean, near the latitudes of Drake Passage, the dominant wind stress is eastward and increases linearly from south to north, so its curl is approximately uniform throughout the region and corresponds to a sink.

To represent this case, a second test with the model was carried out using the same localised source term as before but with a sink term spread uniformly over all the sea points of the model. In this case, not only are there the western boundary currents and zonal jets discussed previously, but there are also Sverdrup gyres driven by the vertical Ekman transport. Because Laplacian viscosity is used in the numerical model and the wind stress curl is constant in an east-west direction, the flow within each gyre should be given by the analytic theory of Munk and Carrier (1950).

The way this splits up the ocean is shown in figure 7. In region I, the vertical Ekman flux produces Sverdrup gyres fed from the source in the north-west corner through a western boundary current. It requires no extra zonal current.

In region II, the Sverdrup gyres are fed from the western boundary current attached to the island and as in the case shown in figure 2, this requires a single strong zonal current to connect it to the western boundary current attached to the northern part of the barrier. In region III, the gyres are fed from a western boundary current attached to the southern part of the barrier. To reach this region the flow must completely cross the passage, so two zonal currents are generated. On the basis of this, 
we would predict northern and southern zonal jets as before plus a series of Sverdrup gyres. The flux in the northern jet and southern jets are predicted to be

$F_{1}=\frac{f_{2}}{\left(f_{2}-f_{1}\right)}\left(F_{I I}+F_{I I I}\right)$,

$F_{4}=\frac{f_{3}}{\left(f_{3}-f_{3}\right)} F_{I I I}$

where $F_{I I}$ and $F_{I I I}$ are the vertical fluxes in regions II and III.

In the numerical model, regions II and III constituted .405 and .298 of the total area of the model ocean. Substituting these values into equation 4.2 and using latitude values with the $100 \mathrm{~km}$ offsets included, we obtain,

$F_{1}=10.6 \mathrm{~Sv}, \quad F_{4}=4.6 \mathrm{~Sv}$.

The stream function and height field for the second numerical model run are shown in figure 8 .

The numerical model flow field is as predicted, with a strong northern jet, a weaker southern jet and a series of gyre flows. The gyre scale flows make it more difficult to estimate the transport in the northern and southern jets. The transport $F_{1}$ (or $F_{4}$ ) has therefore been taken to be the total transport between the island and the northern (or southern) boundaries minus the $0.1 \mathrm{~Sv}$ being upwelled in the regions north-east and south east of the island. Thus,

$F_{1}=10.6 \mathrm{~Sv}, \quad F_{4}=4.7 \mathrm{~Sv}$,

with a possible error of about $0.2 \mathrm{~Sv}$ due to the residual oscillation. These model derived values are both in good agreement with the predictions.

\section{Application to the Southern Ocean}

The ideas of this paper cannot form a complete theory of the Southern Ocean or the Antarctic Circumpolar Current because the full effects of stratification and topography are not included. However it is still of interest to explore how far the simple theory can be applied.

\subsection{Topography in the Drake Passage and Kerguelen Regions}

In models of the Southern Ocean the topography is usually highly idealised. Gill and Bryan (1971) for example, assume that the Southern Ocean has constant depth except for the Drake Passage region where in one of the runs a simple sill is introduced at a depth of $1720 \mathrm{~m}$.

In reality the topography is very complex. The ocean basins of the Southern Ocean reach depths in excess of $5000 \mathrm{~m}$ and these are separated by ridge systems, the Mid-Atlantic Ridge, the South-West and South-East Indian Ridges and the Pacific-Antarctic ridges which generally rise to above $3000 \mathrm{~m}$. In addition the path of the Antarctic Circumpolar Current is blocked by Kerguelen and the Campbell Plateau, both of which rise above $1000 \mathrm{~m}$ depth. 
The Drake Passage region is itself particularly complex. Water from the Pacific can readily reach the Scotia Sea at depths down to $4000 \mathrm{~m}$. It then appears to be blocked by the Scotia Arc. Gordon (1974) shows two large passages through the North and South Scotia Ridges with sill depths near $3900 \mathrm{~m}$ (near $48.3^{\circ} \mathrm{W}, 53.1^{\circ} \mathrm{S}$ and $41.7^{\circ} \mathrm{W}, 61.1^{\circ} \mathrm{S}$ ), but the more recent BAS chart (British Antarctic Survey, 1985) shows maximum depths between 3000 and $3250 \mathrm{~m}$ in the passages. Both Gordon 1974 and BAS (1985) show further passages, with sill depths of about $3000 \mathrm{~m}$, to the north and south of the South Sandwich Islands.

Figure 9a shows the minimum depths, along each latitude line, in each of three important sectors of the Southern Ocean. The minimum depths were derived from the US Navy DBDB5 digitised bathymetric data set. The general topography of the region is shown in figure $9 \mathrm{~b}$.

The solid line section shows the minimum depth in the sector between $80^{\circ} \mathrm{W}$ and $50^{\circ} \mathrm{W}$ which includes the main passage region. The northern and southern boundaries of Drake Passage show up clearly. The fact that the minimum depth in the Scotia Sea itself is much less than the $4000 \mathrm{~m}$ referred to above arises because of the rugged nature of the sea floor in the region. The next dotted section covers the sector between $50^{\circ} \mathrm{W}$ and $20^{\circ} \mathrm{W}$ and includes the South Sandwich Islands. The final dashed section is for the sector between $20^{\circ} \mathrm{W}$ and $90^{\circ} \mathrm{E}$ and includes the Kerguelen continental block.

The figure shows that at depths below $1600 \mathrm{~m}$, zonal flows at the latitude of Drake Passage are blocked by both the eastern end of the Scotia Ridge and by the Kerguelen Plateau. However because of the large gaps in both the North and South Scotia Ridges, at depths above $3000 \mathrm{~m}$ the latitudes of Drake Passage are not fully blocked but only occluded.

\subsection{The Ekman Return Flow}

Results from the FRAM model of the Southern Ocean (Döös and Webb, in preparation) and from other models (Manabe et al 1990, Semtner and Chervin 1992) indicate that there is a strong southward transport across the latitudes of Drake Passage at depths of between $1000 \mathrm{~m}$ and $3000 \mathrm{~m}$. This is the return flow which compensates for the northward flow in the Ekman layer. In the FRAM model this flow has a magnitude of $22 \mathrm{~Sv}$ at $53^{\circ} \mathrm{S}$ on the north side of Drake Passage, reducing to $9 \mathrm{~Sv}$ at $61^{\circ} \mathrm{S}$ on the south side.

Studies of the balance of terms in the momentum equation of the FRAM model indicate that this southward return flow is balanced by topographic pressure gradient terms (Stevens and Ivchenko, in preparation). The return flow most likely occurs as a western boundary current adjacent to the topography.

However because the latitudes of Drake Passage are not completely blocked at these depths but only occluded, the western boundary current must detach itself from the South American continent and continue as a boundary current on one of the off-shore features. In this case a theory, like the one of this paper, must apply. 


\section{Application of the theory to the Southern Ocean}

The results of the earlier thought experiments indicate that of the two main barriers, Kerguelan and the Scotia Arc, that occlude Drake Passage between 1600m and 3000m, Kerguelen should have the dominant effect. It is the most easterly of the two barriers, and although it only extends a similar distance to the south, it extends furthest to the north.

If we treat the Southern Ocean between $1600 \mathrm{~m}$ and $3000 \mathrm{~m}$, as being equivalent topologically to figure 4, then y1 equals $46^{\circ} \mathrm{S}$, the northern limit of Kerguelen and y2 equals $57^{\circ} \mathrm{S}$, the southern limit of the South American continental shelf. From equation 3.3, a flux F crossing Drake Passage will produce a northern zonal current in the South Atlantic sector equal to,

$$
\begin{aligned}
F_{1} & \left.\left.=f\left(57^{\circ}\right) /\left(f\left(57^{\circ}\right)\right)-f\left(46^{\circ}\right)\right)\right) F, \\
& =7.0 \mathrm{~F} .
\end{aligned}
$$

If the zonal currents are assumed to be offset by 1 degree then the flux becomes $6.0 \mathrm{~F}$.

The flux $\mathrm{F}$ to use in this equation is the Ekman transport between regions II and I of figure 7. This flux has been calculated, using an annual average of the Hellerman and Rosenstein (1983) monthly wind stress fields ${ }^{1}$, for a section running from South America to Kerguelen at a latitude of $57^{\circ} \mathrm{S}$, then north along $50^{\circ} \mathrm{E}$ and finally eastwards along $46^{\circ} \mathrm{S}$ to South America. It gives a total transport of 25 Sv.

Substituting this figure in equation 40, gives a total transport in the northern zonal jet of $176 \mathrm{~Sv}$. This reduces to $151 \mathrm{~Sv}$ when using a 1 degree offset for the zonal currents. Given the approximations involved, these figures are surprisingly good. Field observations (Nowlin and Klinck, 1986) indicate transports through Drake Passage of around 134 Sv. Model results (Cox 1975, Semtner and Chervin 1988, 1992, The FRAM group 1991), give values nearer $190 \mathrm{~Sv}$. At the end of the initial six year robust diagnostic phase of the FRAM model run, $127 \mathrm{~Sv}$ flowed north of the Kerguelen Plateau, 48 Sv flowed south and $35 \mathrm{~Sv}$ flowed through the small gap in the plateau at $56^{\circ} \mathrm{S}$. After a further four model years, during which it was running freely, the figures were 127, 48 and 21 Sv respectively.

These results imply that the predicted transport of the current passing north of Kerguelen is too high. However, as was shown earlier, additional occluding barriers should reduce the total transport so the error has the right sign.

The present results are also close to the estimates of $173 \mathrm{~Sv}$ and $190 \mathrm{~Sv}$ for the strength of the Antarctic Circumpolar Current obtained by Baker (1982) using Sverdrup transport theory. Again he was concerned primarily with the northern branch of the current. There are connections between the two theories but the present one is better at explaining why the circulation is completed by a flow through Drake Passage.

\footnotetext{
${ }^{1}$ The data set used was an annual average of the monthly wind stress file included in the "Data Set Atlas for Oceanographic Modelling" compiled by the GFDL Laboratory, Princeton. This $1^{\circ}$ by $1^{\circ}$ data set is based on the Hellermann and Rosenstein $2^{\circ}$ by $2^{\circ}$ gridded data.
} 
However the present theory fails when extended either to the current flowing south of the Kerguelen or to the case where the Scotia Arc is treated as the western boundary of an additional gyre. In the case of the southern jet, the southern boundary of Drake Passage occurs near $60{ }^{\circ} \mathrm{S}$ (for flows through the deep gap) and the southern edge of Kerguelen occurs near $64^{\circ} \mathrm{S}$. If these values are used in equation 3.3, then the amplification factor is 26 . (This reduces to 17 if the currents are offset by an extra degree).

For the flux F, we can integrate the Hellerman and Rosenstein annual mean wind stress field along $63^{\circ} \mathrm{S}$. (This corresponds approximately to the boundary between sections II and III of figure 7). The northward Ekman transport is $6.7 \mathrm{~Sv}$, giving from equation 3.5 a transport of $177 \mathrm{~Sv}$ south of the Kerguelen Plateau. (This becomes 117 Sv using the smaller amplification factor). These values are unrealistically large.

A similar problem arises when the Scotia Arc is treated as the western boundary of a separate gyre extending eastwards to Kerguelen. If the northern and southern limits of the Scotia Arc are taken to be at $53^{\circ} \mathrm{S}$ and $61^{\circ} \mathrm{S}$ and if we assume the South Sandwich Islands form a continuous barrier, then the amplification factors for this gyre (equation 3.9) are 11.5 and -10.5.

The Ekman flux out of the region between the Scotia Arc and the Kerguelen Plateau is 5.6 Sv. With the amplification factors this gives total transports around the Scotia Arc, $\left(F_{5}\right.$ and $F_{6}$ in figure 5), of $64 \mathrm{~Sv}$ eastwards and $59 \mathrm{~Sv}$ westwards. Such flows are not unreasonable and might be hidden amongst the other gyre flows of the region. However to support this gyre the model requires unrealistic currents of 845 Sv north of the Kerguelen Plateau and 901 Sv continuing across the Pacific. This failure of the model needs further study.

\section{Conclusions}

It has been shown that a meridional current can cross an occluded zonal channel, as a series of western boundary currents on the land masses spanning the channel. As a by-product of the meridional flow, a series of strong zonal jets are also produced.

It has also been shown that between $1600 \mathrm{~m}$ and $3000 \mathrm{~m}$ the Southern Ocean has the properties of an occluded zonal channel. These are also the depths of the return flow of the surface Ekman Layer. In the return flow the angular momentum, initially gained from the wind in the surface Ekman layer, is finally lost to the solid earth through topographic form drag.

If the simple occluded channel model is applied to the Southern Ocean then it is found to give reasonable agreement with the observed transport of the Antarctic Circumpolar Current flowing north of Kerguelen. However the transport the simple model predicts south of Kerguelen is not observed, neither are the strong currents produced by upwelling to the east of the Scotia Arc.

Acknowledgements. I would like to acknowledge the work of others members of the FRAM group, especially Kristofer Ds, David Stevens and Vladimir Ivchenko, whose investigations on the circulation of the Southern 
Ocean stimulated the present paper. Thanks also to Tim Hateley who carried out the runs of the one-layer numerical model and to Beverly de Cuevas for careful reading of the draft paper.

\section{Appendix A Stream Function Solution for an East-west Jet}

From eqn 2.10, the stream function equation for a time independent east-west jet, away from the eastern and western boundary regions, is,

$\rho \beta \frac{\partial \phi}{\partial x}=A \frac{\partial^{4} \phi}{\partial y^{4}}$.

This is mathematically similar to the thermocline equation (Pedlosky, 1969). We look for a solution with a unit delta function source on the eastern boundary. If the eastern boundary is defined by $x$ equal to zero and if the source is at $y$ equal zero, then along the boundary the stream function is,

$$
\begin{aligned}
\phi(0, y)=\theta(y), \text { where } \theta(y) & =1 \text { for } y>0, \\
& =0 \text { for } y<0 .
\end{aligned}
$$

Let $\tau$ equal $-(A /(\rho \beta)) x$. Then,

$\frac{\partial \phi}{\partial \tau}=-\frac{\partial^{4} \phi}{\partial y^{4}}$

This is a biharmonic diffusion equation with $\tau$ taking the place of time. In terms of its Fourier transform $a_{k}(\tau)$,

$$
\begin{aligned}
\phi(y, \tau) & =\frac{1}{2 \pi} \int_{-\infty}^{\infty} d k a_{k}(\tau) e^{i k y} \\
a_{k}(\tau) & =\int_{-\infty}^{\infty} d y \phi(y, \tau) e^{-i k y} .
\end{aligned}
$$

Substituting in A.1,

$\frac{\partial a_{k}(\tau)}{\partial \tau}=-(i k)^{4} a_{k}(\tau)$.

From equations $\mathrm{A} 2$ and $\mathrm{A} 5$, this has the solution,

$a_{k}(\tau)=a_{k}(0) e^{-k^{4} \tau}$,

where,

$a_{k}(0)=\int_{0}^{\infty} d y e^{-i k y}$

If $k$ is real the integral has no solution, but if we set $k=k_{0}-i \epsilon$, where $k_{0}$ is real and $\epsilon$ is real and positive, then there is a solution valid in the limit $\epsilon->+0$. This is the one needed, namely,

$a_{k}(0)=\operatorname{Lim}_{\epsilon->+0}[i(k-i \epsilon)]^{-1}$

Substituting A7 and A9 in A4,

$\phi(y, \tau)=\frac{1}{2 \pi} \operatorname{Lim}_{\epsilon->+0} \int d k \frac{1}{i(k-i \epsilon)} e^{i k y-k^{4} \tau}$. 
In terms of the Cauchy principal of the integral (represented by P), it is,

$\phi(y, \tau)=\frac{1}{2}+\frac{1}{2 \pi} P \int_{-\infty}^{\infty} d k \frac{1}{i k} \exp \left(i k y-k^{4} \tau\right)$.

Let $k^{\prime}$ equal $k \tau^{1 / 4}$ and let $z$ equal $y / \tau^{1 / 4}$. Then,

$$
\begin{aligned}
\phi(y, \tau) & =\phi(z) \\
& =\frac{1}{2}+\frac{1}{2 \pi} P \int_{-\infty}^{\infty} d k^{\prime} \frac{1}{i k^{\prime}} \exp \left(i k^{\prime} z-k^{4}\right)
\end{aligned}
$$

and,

$\frac{\partial \phi}{\partial z}=\frac{1}{2 \pi} \int_{-\infty}^{\infty} d k^{\prime} \exp \left(i k^{\prime} z-k^{\prime 4}\right)$

This is related to the east-west velocity,

$u(x, y)=\frac{1}{H t^{1 / 4}} \frac{\partial \phi}{d z}$.

These solutions for $\phi$ and $\partial \phi / \partial z$ are shown in figure 10. There is a central jet, symmetric about the central latitude with small return flows to the north and south.

Equations A12 and A13 are similarity solutions, showing that the flow depends only on the parameter $z$. The flow is predominantly zonal in the west and becomes convergent near the eastern boundary. The behaviour can be seen in the solutions obtained from the reduced gravity model (figures 6 and 8). However in the model there are also viscous effects near the eastern and western boundary layer regions which were neglected in deriving equation A.1.

The above solution can be extended to the case of a more general source or sink $S(y)$ on the eastern boundary. From A.3,

$\phi(y, \tau)=\frac{1}{2} \int_{-\infty}^{\infty} d y^{\prime} S\left(y^{\prime}\right)+\frac{1}{2 \pi} \int_{-\infty}^{\infty} d k \frac{1}{i k} \int_{-\infty}^{\infty} d y^{\prime} \exp \left(i k\left(y-y^{\prime}\right)-k^{4} \tau\right) S\left(y^{\prime}\right)$.

\section{Appendix B Changes in the Zonal Transport due to Secondary Islands}

This appendix considers effects of islands or topographic features which interfere with the flow but otherwise are not required to occlude the channel. The simplest case, where an island blocks one of the zonal jets, forming two new jets which terminate at the same western boundary current, is shown in figure 11.

Let the initial zonal jet be at latitude $y_{j}$, with flux $F_{j}$, and the two new jets be at latitudes $y_{n}$ and $y_{s}$, with fluxes $F_{n}$ and $F_{s}$. We assume that both jets terminate at the same north-south barrier. Let the pressure to the west of the secondary island be $P_{c}$ and the pressures to the north and south be $P_{n}$ and $P_{s}$. Then,

$P_{n}-P_{c}=\rho f_{n} F_{n}$,

$P_{c}-P_{s}=\rho f_{s} F_{s}$,

$P_{n}-P_{s}=\rho f_{j} F_{j}, \quad F_{j}=F_{n}+F_{s}$. 
Eliminating the pressure terms gives,

$$
\begin{aligned}
& F_{n}=F_{j} \frac{f_{s}-f_{s}}{f_{n}-f_{s}}, \\
& F_{s}=F_{j} \frac{f_{n}-f_{j}}{f_{n}-f_{s}} .
\end{aligned}
$$

In such cases the total zonal flow is unchanged. It is split between the two new jets with the greatest weight to the jet nearest to the original latitude.

The cases where the new zonal jets finish on different western boundaries are more complex. Three examples involving two islands are shown in figures 12a, b and c. (The remaining two island cases are obtained by reflecting these examples through their central latitude).

In figure 12a, the extra island upstream of the occluding island forms one jet which terminates on the original western boundary and a second terminating on the occluding island.

The example is very similar to that of figure $4 \mathrm{a}$, except that the downstream island now occludes the whole channel. Solving the problem as before, gives the same equations for the fluxes $F_{1}, F_{2}$, $F_{3}$ and $F_{4}$. The total flux is,

$F_{t o t}=F_{2}+F_{b}^{\prime}+F_{4}+F$

where,

$F_{b}^{\prime}=\frac{f a-f_{1}}{f_{2}-f_{1}} \frac{f_{2}}{f_{a}} F_{b}$,

and the unprimed fluxes are those given by equation 3.7.

In the case shown in figure $12 \mathrm{~b}$, the equations for the fluxes $F_{1}, F_{2}, F_{a}$ and $F_{b}$ are unchanged. The total flux is,

$F_{t o t}=F_{2}+F_{b}+F_{4}^{\prime}+F$

where,

$F_{4}^{\prime}=\frac{f_{3}-f_{a}}{f_{b}-f a} \frac{f_{b}}{f_{3}} F_{4}$.

The case of figure $12 \mathrm{c}$ is unusual in that both islands occlude the channel and intersect each others zonal current system. The fluxes $F_{1}$ and $F_{2}$ are given by the same equations as before but there are changes in the other fluxes. The total flux is given by,

$F_{t o t}=F_{2}+F_{b}^{\prime}+F+F_{4}$

where,

$F_{b}^{\prime}=\frac{f_{4}-f_{b}}{f_{4}-f_{3}} \frac{f_{a}-f_{1}}{f_{2}-f_{1}} \frac{f_{2}}{f_{a}} F_{b}$,

and again the unprimed fluxes are given by equation 3.7.

In all three cases the total transport is increased by adding the extra island, but as the term in square brackets is less than one, the total zonal transports are always less than if the two islands had been part of an occluding chain of islands. 
It would thus appear that extra islands (or other topographic obstructions), either have no effect on the total zonal transport or increase it to an amount which is less than that generated when they are essential for occluding the channel. 


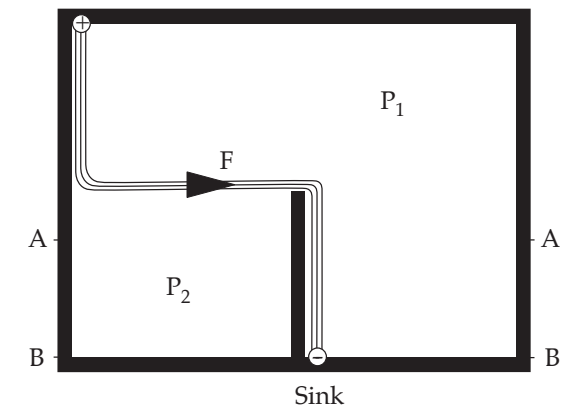

Fig. 1. Figure 1. Source and sink flow in a simple ocean basin with a partial barrier. The solution is made up of two western boundary currents and a zonal current, with constant pressure in the regions $P_{1}$ and $P_{2}$. If the domain is periodic in an east-west direction and the barrier between A and B is removed, then this can no longer be a solution.

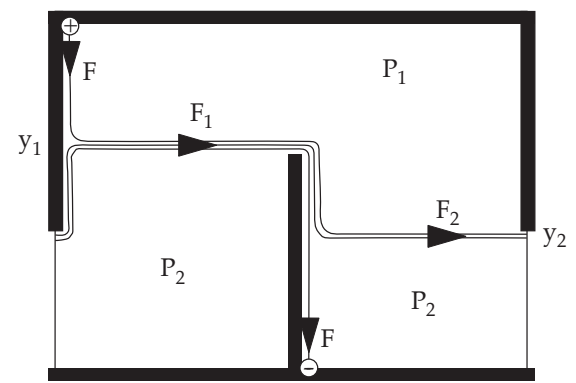

Fig. 2. Figure 2. Source and sink flows in a zonal channel, (periodic in the east-west direction), with occluding barriers.

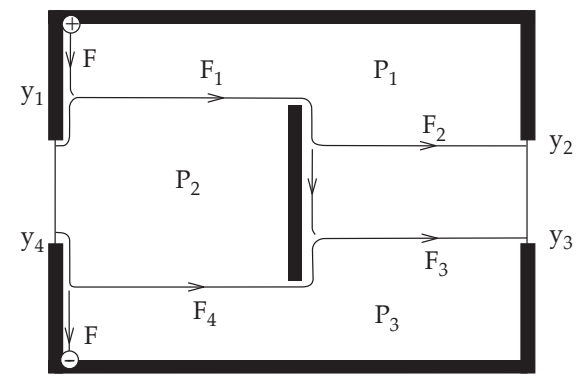

Fig. 3. Figure 3. Source and sink flows in a zonal channel with occluding island. 

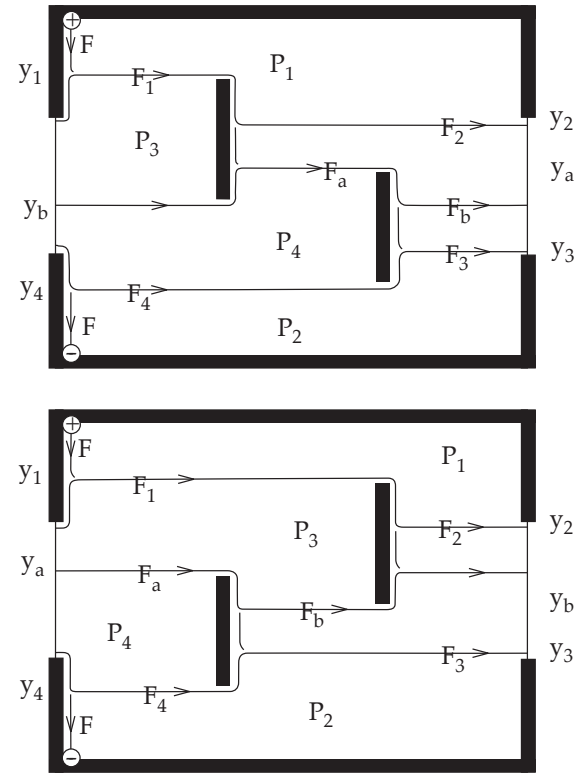

Fig. 4. Figure 4. Source and sink flows in a zonal channel with two islands occluding the channel.

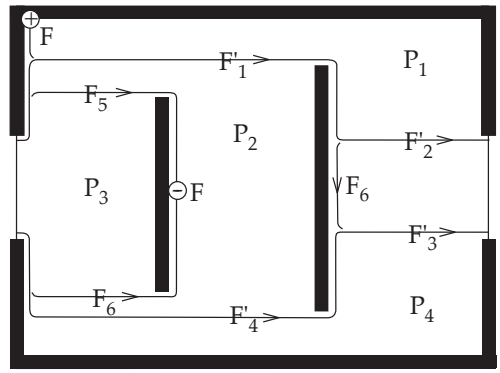

Fig. 5. Figure 5. Source and sink flows in a zonal channel, occluded by two islands, with the sink on the eastern boundary of the western island. 

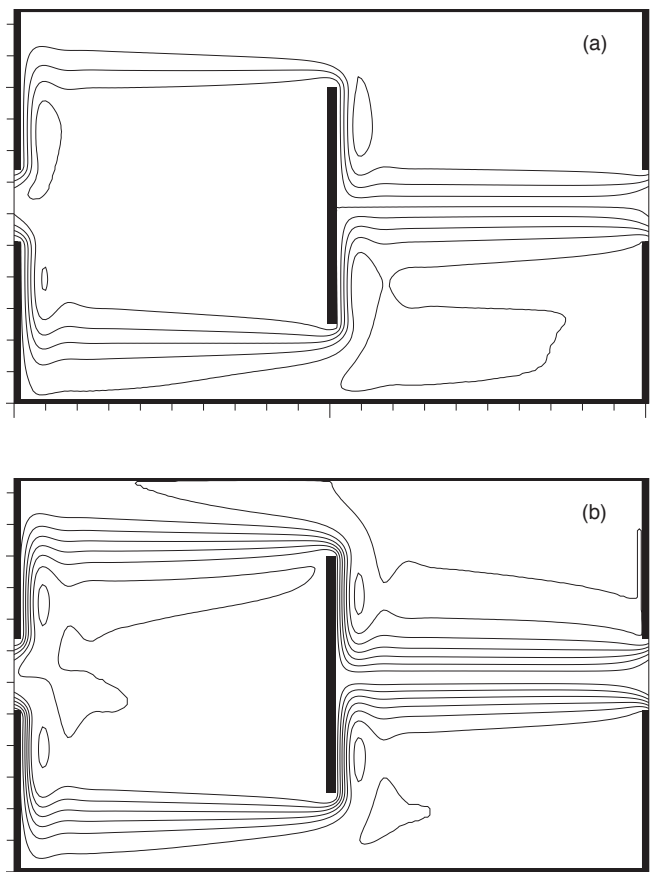

Fig. 6. Figure 6. The (a) height and (b) the stream function fields at the end of the first numerical model run. The model was started from rest with $1 \mathrm{~Sv}$ sources and sinks in the north-west and south-west corners of the main basin. The height field is contoured at intervals of $25 \mathrm{~cm}$, the stream function at intervals of $2.5 \mathrm{~Sv}$.

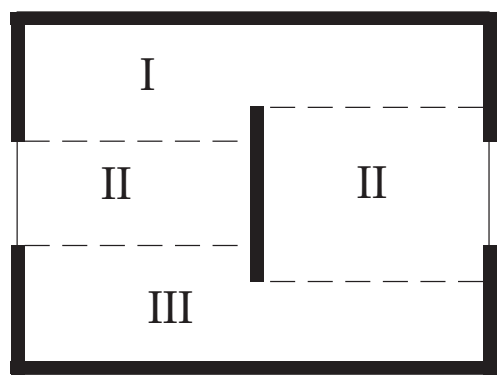

Fig. 7. Figure 7. The three upwelling provinces in a zonal channel with occluding island. The Sverdrup flow in each province is associated with a separate western boundary current. 

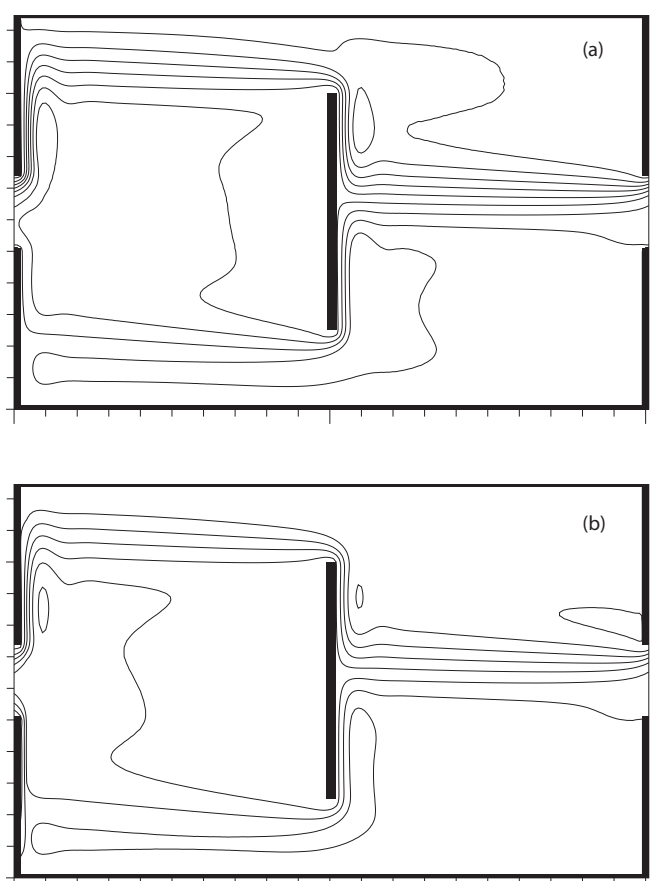

Fig. 8. Figure 8. The (a) height and (b) stream function fields at the end of the second numerical model run. The model was started from rest with a $1 \mathrm{~Sv}$ source in the north-west corner of the main basin and a $1 \mathrm{~Sv}$ sink spread uniformly over the rest of the model ocean. The height field is contoured at intervals of $25 \mathrm{~cm}$, the stream function at intervals of $2.5 \mathrm{~Sv}$. 
(a)

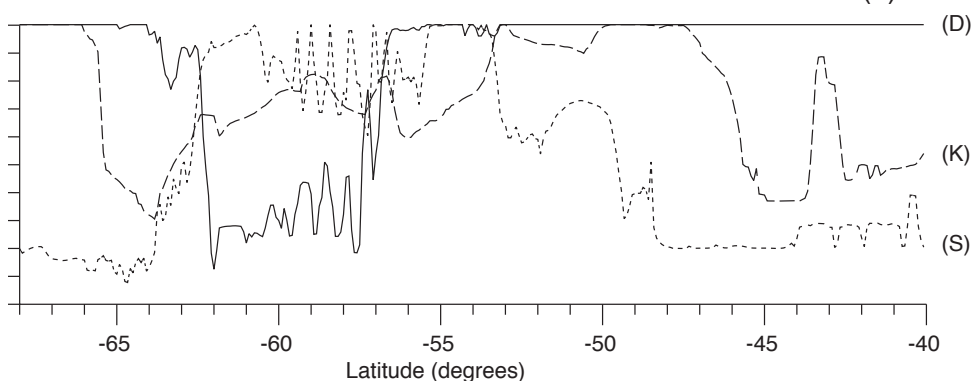

(b)

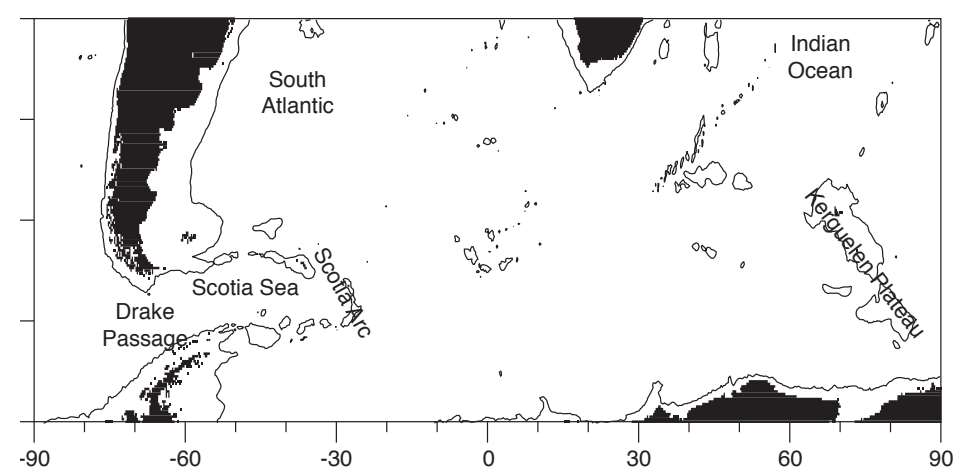

Fig. 9. Figure 9 (a) Minimum depths in (D) the Drake Passage sector between $80^{\circ} \mathrm{W}$ and $50^{\circ} \mathrm{W}$, (S) the sector between $50^{\circ} \mathrm{W}$ and $20^{\circ} \mathrm{W}$ including the eastern end of the Scotia Arc, and (K) the Kerguelen Plateau sector between $20^{\circ} \mathrm{W}$ and $90^{\circ} \mathrm{E}$. (b) Topography of the Southern ocean between $90^{\circ} \mathrm{W}$ and $90^{\circ} \mathrm{E}$. The thin line represents the $2000 \mathrm{~m}$ contour. 


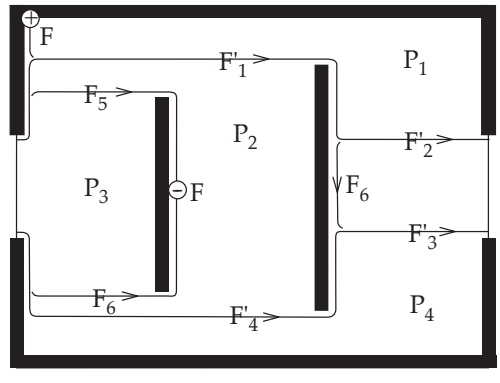

Fig. 10. Figure 10. The (a) stream function and (b) stream function gradient for the similarity solution of the east-west jet.

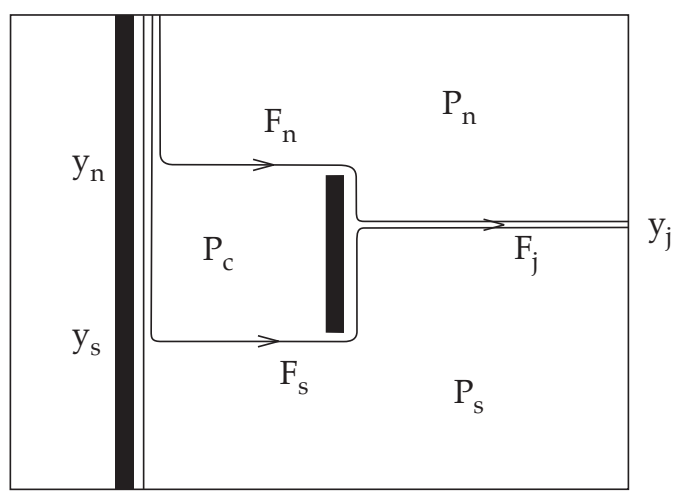

Fig. 11. Figure 11. Flows when an off-shore island blocks a zonal jet $F_{j}$. 
(a)

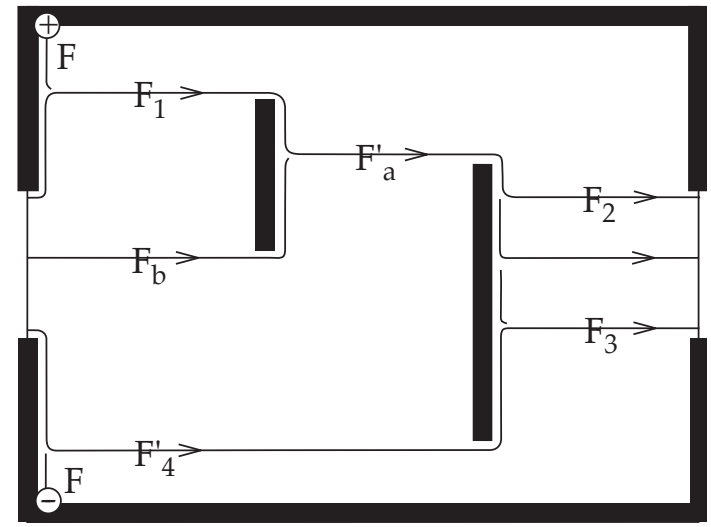

(b)

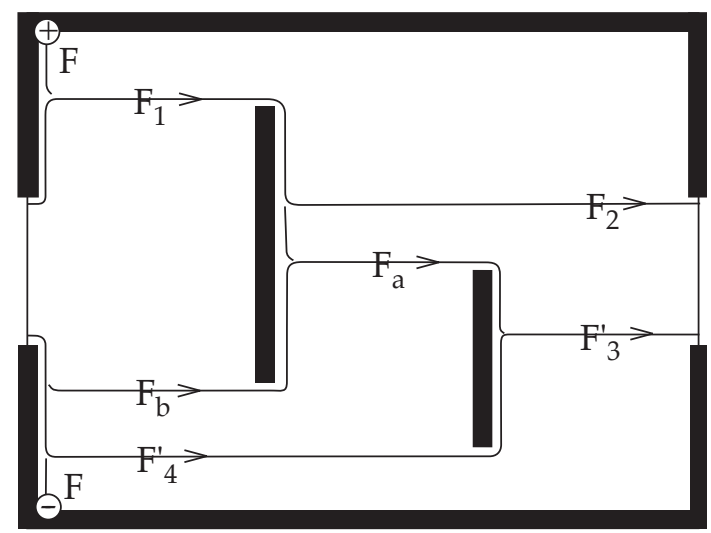

(c)

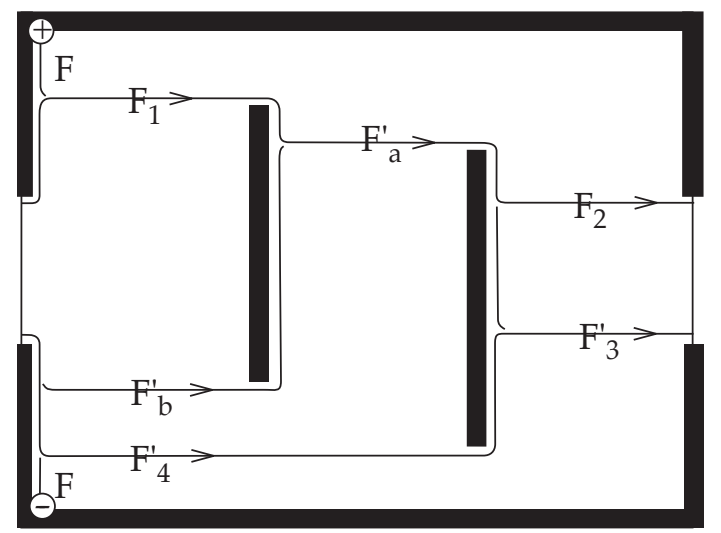

Fig. 12. Figure 12. Source and sink flows in an occluded zonal channel with a secondary island. 


\section{References}

Baker, D.J., "A note on the Sverdrup balance of the southern ocean," Journal of Marine Research, 40 (Supplement), 21-26 (1982).

British Antarctic Survey, Tectonic map of the Scotia Arc, 1:3000000, BAS (Misc) 3. British Antarctic Survey, Cambridge, (1985).

Cox, M.D., "A baroclinic numerical model of the world ocean: preliminary results", in: Reid, R.O. et al, Numerical Models of Ocean Circulation, National Academy of Sciences, Washington, D.C., 364pp (1975).

Gill, A.E., "Models of equatorial currents", in: Reid, R.O. et al, Numerical models of ocean circulation. National Academy of Sciences, Washington D.C., 364 pp (1975).

Gill, A.E. and Bryan, K., "Effects of geometry on the circulation of a three dimensional southern hemisphere ocean model”, Deep-Sea Research, 18, 685-721 (1971).

Gill, A.E., Ocean-atmosphere dynamics, Academic Press, New York, London, 662pp (1982).

Gordon, A.L., "International Southern Ocean Studies”, in: Polar Oceans - Proceedings of polar oceans conference May 1974, Montreal, Canada, ed: Dunbar, M.J., Antarctic Institute of North America (1977).

Hellerman, S. and Rosenstein, M., "Normal monthly wind stress over the world ocean with error estimates", Journal of Physical Oceanography, 13, $1093-1104$ (1983).

Johnson, G.C. and Bryden, H.L., "On the size of the Antarctic Circumpolar Current”, Deep-Sea Research, 36(1), 39-53 (1989).

LeBlond, P.H. and Mysak, L.E., Waves in the ocean, Elsevier Scientific Publishing Company, Amsterdam, Oxford, New York, 602pp (1978).

Manabe, S., Bryan, K. and Spelman, M.J., "Transient response of a global ocean-atmosphere model to a doubling of atmospheric Carbon Dioxide”, Journal of Physical Oceanography, 20, 722-749 (1990).

Messinger, F. and Arakawa, A., "Numerical methods used in atmospheric models", GARP Publication series, No. 17, World Meteorological Organisation, Geneva, 64pp (1976).

Munk, W.H., "On the wind-driven ocean circulation”, Journal of Meteorology, 7 (2), 79-93 (1950)

Munk, W.H. and Carrier, G.F., "The wind-driven circulation in ocean basins of various shapes", Tellus, 2, 158-167 (1950).

Munk, W.H., \& Palmen, E., "Note on the dynamics of the Antarctic Circumpolar Current”, Tellus, 3, 53-55 (1951).

Nowlin, W.D. and Klinck, J.M., "The physics of the Antarctic Circumpolar Current”, Reviews of geophysics, 23(4), 469-491 (1986).

Pedlosky, J., "The linear theory of circulation in a stratified ocean”. Journal of Fluid Mechanics, 35(1), 185-205 (1969).

Saunders, P.M. and Thompson, S.R., "Transport, heat and freshwater fluxes within a diagnostic numerical model (FRAM)", Journal of Physical Oceanography, (1992, in press).

Semtner, A.J. and Chervin, R.M., "A simulation of the global ocean circulation with resolved eddies", Journal of Geophysical Research, 93, 15502-15522 and 15767-15775 (1988).

Semtner, A.J. and Chervin, R.M., "Ocean general circulation from a global eddy-resolving model”, Journal of Geophysical Research, 97, 5493-5550 (1992).

Stommel, H., ”A survey of ocean current theory", Deep-Sea Research, 4, 149-184 (1957). 
Stommel, H., The Gulf Stream: a physical and dynamical description, 2nd edition, University of California Press, Berkeley (1965).

The FRAM Group (Webb, D.J. et al) "An Eddy-Resolving Model of the Southern Ocean”, Eos, Transactions, American Geophysical Union, 72(15), 169-174, 1991. 